\title{
Documenting Patient Data in Psoriasis Clinical Practice-Patient Focus Groups Supporting Psoriasis Experts' Decision-making
}

This article was published in the following Dove Press journal: Patient Preference and Adherence

\section{Marina Otten (iD) \\ Matthias Augustin (DD}

German Center for Health Services Research in Dermatology (CVderm), Institute for Health Services Research in Dermatology and Nursing (IVDP), University Medical Center HamburgEppendorf (UKE), Hamburg, Germany
Correspondence: Marina Otten

German Center for Health Services Research in Dermatology (CVderm), Institute for Health Services Research in Dermatology and Nursing (IVDP), University Medical Center HamburgEppendorf (UKE), Martinistraße 52, Hamburg, 20246, Germany

$\mathrm{Tel}+4940741055428$

Fax +49407410 55348

Email m.otten@uke.de
Background and Objectives: This article presents patients' attitudes about documenting patient data and outcome measures in psoriasis clinical practice to support a Delphi approach of psoriasis experts to develop a standard data set.

Patients and Methods: We conducted three focus groups with 14 patients in a German outpatient unit for psoriasis. The focus was to explore reasons for and against the documentation of single variables concerning personal, anamnesis, clinical, patient-reported outcomes, and other data.

Results: The patients mainly discussed if a variable has an impact on the disease or treatment decision, or if there might be a practical value from experiences with treatments when documented. In addition, in their point of view, patient-reported outcome data are important to document as it enables physicians to learn about a patient's subjective burden of disease. Patient education and the involvement of other physicians in the treatment process also emerged as relevant aspects.

Conclusion: The results help to understand patients' preferences on documenting patient data and their idea of an exhaustive doctor-patient consultation to improve doctor-patient communication, disease monitoring, and quality of care.

Keywords: psoriasis, patient involvement, focus groups, documentation, patient data

\section{Introduction}

The World Health Organization (WHO) included psoriasis in the list of the world's most serious noninfectious diseases because it is a challenging medical condition. ${ }^{1}$ It is a common, chronic, noncommunicable, painful, disfiguring, and disabling skin disease with an unpredictable course of symptoms. Psoriasis causes great physical, emotional, and social burden ${ }^{2,3}$ with a marked loss of productivity and a great negative impact on patients' quality of life. ${ }^{1}$ Care for patients with psoriasis not only requires treating the symptoms, such as skin lesions, joint and nail involvement, but also reducing pain and disability from arthritis and other manifestations. Several comorbidities must also be identified and managed, eg, arthritis, hypertension, dyslipidemia, diabetes mellitus, and cardiovascular disorders, such as myocardial infarction, stroke, and psychological conditions. ${ }^{1}$ Patients with psoriasis often need lifelong treatment and as the course of the disease is very individual, there is a high need for optimizing patient-centered care. Therefore, recording and interpretation of clinical tools and patient-reported outcomes (PRO) to achieve 
considerable health-related quality of life in psoriasis care are essential. Hence, standardized sets for psoriasis documentation and definitions of clinically meaningful outcomes are important components. ${ }^{1}$ Yet, no data sets have been systematically developed to document psoriasis for the use in clinical practice in Germany.

In order to establish a data set including patient data and outcome measurements in psoriasis care, we initiated a German national consensus group in 2017 in cooperation with national dermatological institutions. Within five Delphi rounds (online and in-person), the consensus group developed a core, optimal, and optional data set (to be published elsewhere).

The aim of this study was to inform the psoriasis experts' decision making by exploring patients' attitudes towards documenting patient data and outcome measures in clinical practice. Thereby, we detected the patients' reasons for and against the documentation of single variables. The results also help to understand patients' preferences and their idea of an exhaustive doctor-patient consultation.

The longitudinal aim is to develop an electronic toolbox providing clinical and patient-reported outcomes for practice to facilitate data collection, data storing, and visual data providing.

\section{Patients and Methods}

It is recommended to include patients within the methodological framework of developing data sets in dermatology. ${ }^{4}$ As there were no comparable data available and we aimed to detect reasons for and against documenting variables in psoriasis care, we chose a qualitative approach. We conducted focus groups because they allow for needs assessment, enable discussions, and give participants the chance to build their ideas with each other and on the ideas of the others. ${ }^{5}$ Beforehand, we detected variables that could be considered for documenting psoriasis in clinical care with the help of literature reviews of psoriasis guidelines and registers. Then the psoriasis experts reached preliminary consensus on these variables in the Delphi rounds. At the same time, the variables served as the basis for a semi-structured guideline in the qualitative focus group study presented here. The guideline included 59 variables that can be summarized by the following topic areas: personal data, anamnesis data, clinical data, patient-reported data, and other data. The manuscript follows the STROBE guideline where applicable.

\section{Participants and Recruitment}

We conducted three focus groups with a total of 14 patients with psoriasis, ranging from four to five participants each. We recruited patients from an outpatient care unit for psoriasis of a large University Medical Center in Germany. Due to the specialized care in the outpatient center, the sample might mainly consist of patients with moderate and severe psoriasis. Inclusion criteria were age above 18, being proficient in German, and a psoriasis diagnosis. The patients received $€ 50$ for participation compensation. We targeted heterogeneity of the sample in terms of age, gender, and time of occurrence of symptoms.

\section{Ethical Considerations}

According to the ethics commission of the Medical Association of Hamburg, no ethics vote was required because of anonymous and noninterventional data collection. All participants gave written informed consent prior to participation, which included publication of anonymized responses. We ensured confidentiality by not entering any names or other identifying information into the transcripts. The study was conducted in accordance with the Declaration of Helsinki.

\section{Data Collection}

We conducted all focus groups using a semi-structured guideline. On average, the interviews lasted $84 \mathrm{~min}(56$, 86, and $109 \mathrm{~min}$ ). The patients discussed each of the variables in terms of to what extent they should be documented or discussed with a physician. Thereby, DIN A0 posters showing the variables for each of the five topic areas allowed the patients to have an overview and to summarize variables while pointing out their reasons for or against a documentation. The moderator guided the group discussion, ensured opportunities for all participants to speak, encouraged open discussion, and ensured a discussion on the topics of interest. At the end, the participants filled out a questionnaire on sociodemographic characteristics.

\section{Data Analysis}

We fully recorded, transcribed (160 pages: Calibri 12 , line spacing 1.15), and subjected the interviews to content analysis to develop a category system. Two qualitative coders independently read and analyzed the focus group transcripts to develop categories for each of the subject areas. After we had analyzed the transcripts, we conducted 
an interrater reliability check. When there was no consensus on allocating quotations, we discussed, modified, and reallocated the quotation and/or category until interrater reliability was ensured (79\%). We developed the main categories and some subcategories deductively because for every variable a decision on the necessity of documenting and reasons for and against documenting should be explored. We developed all subcategories concerning the reasons inductively with no remaining rest categories (Figure 1). Figure 2 shows an example of how we categorized one of the quotations. In this way, we ensured a valid category system. The category system also achieved theoretical saturation as no new themes, ie, reasons, emerged during the analysis of the third focus group. Furthermore, we allocated all text passages selected as relevant for the analysis to a category (exhaustion) and to only one category (exclusion). Finally, we performed coding frequencies. The category system resulted in 51 subject areas (resulting from 59 variables) because the patients summarized some variables while giving reasons. We developed main and subcategories for all 51 variables (when applicable) (Figure 1).

\section{Results}

Nine men and five women participated in the focus groups. Their mean age was 47 years, ranging from 29 to 73 years. The participants had mainly medium and higher education (secondary school certificate or higher). The mean elapsed times since first diagnosis and first symptoms were 28 (range: 2-50 years) and 29 years (range: 3-50 years).

For the 51 subject areas (variables) altogether 135 main categories emerged, of which only eight concerned the documentation of a variable over time (Figure 1). In total, the analyses resulted in 209 subcategories (Figure 1). Of those, 82 concerned the decision on whether a variable should be documented or not (yes: $n=50$ with 153 mentions; no: $\mathrm{n}=12$ with 24 mentions; undecided: $\mathrm{n}=20$ with 27 mentions). The other 127 subcategories reflected reasons given for documenting a variable $(n=90$ with 184 mentions) or against it ( $\mathrm{n}=37$ with 58 mentions).

Following, we present the results for each of the five predefined topic areas. We summarized the results of the decision on whether a variable should be documented or not. This was the case because it was a qualitative approach and not every patient had to or was asked to give an answer on this question. We only categorized the answer if a patient mentioned it independently. That is why we do not show $\mathrm{N}$ as it would not be valid information.

The topic area "personal data" existed of 16 subject areas. In the patients' opinion, the following of those should rather be documented: current and previous occupation, current family planning, age, weight, smoking, and drinking behavior. Insurance and educational status as well as waist and hip circumference do not necessarily have to be documented. The patients were undecided about

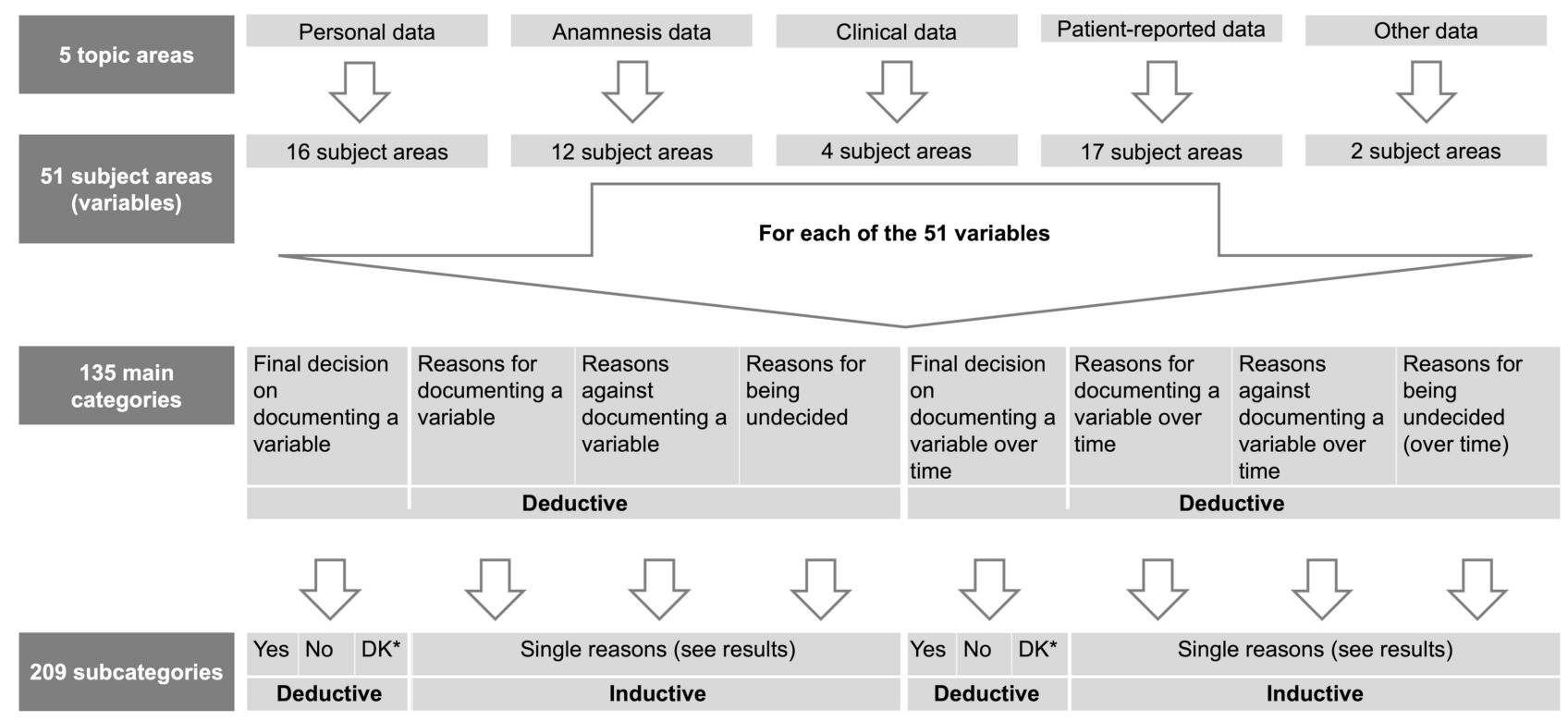

Figure I Overview of the structure of analyses. Note: *Do not know. 


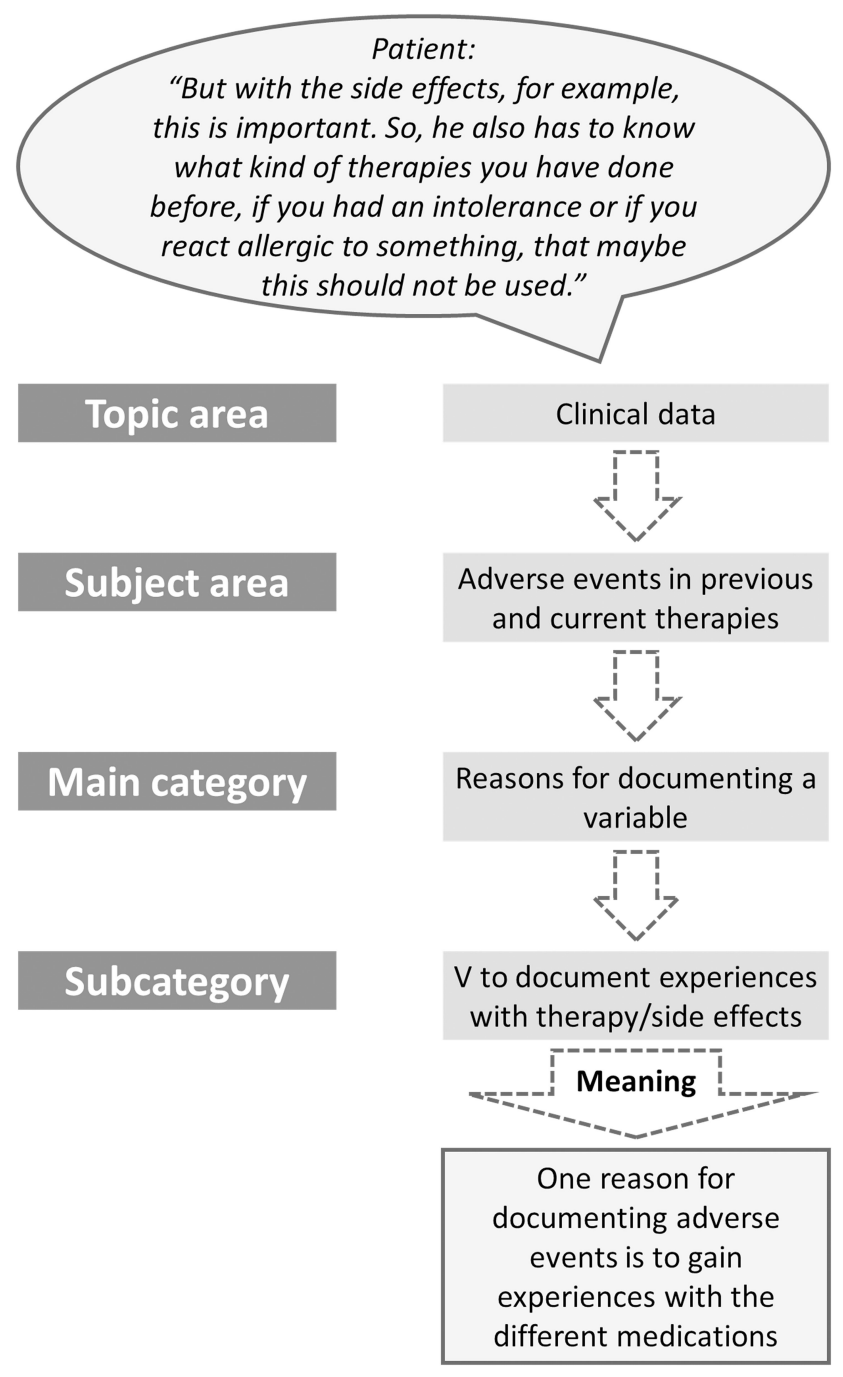

Figure 2 Example of the categorization of a quotation. Abbreviation: $\mathrm{V}$, variable.

documenting marital status, previous pregnancies, family history of psoriasis, gender, height, body mass index, and nutrition. The patients' opinions were unambiguous about the variables educational status and physicians/physician groups involved in treatment as well as about the variables concerning anamnesis data, clinical data, and patientreported data. They pointed out that these variables should be documented and they mainly stated reasons for documentation. The topic area anamnesis data existed of 12 and the topic area clinical data of four subject areas. There was high agreement on the importance of documentation, as a higher number of patients spoke out for documenting each subject area. The topic area patient-reported data consisted of 17 subject areas. The patients were undecided about the documentation of patient satisfaction, but stated that all other subject areas should be documented. Patients also gave a vote for two further subject areas. They voted for the documentation of previous and current patient education. Beyond that, the patients were of the opinion that physicians/physician groups involved in the treatment should be recorded.

For each topic area, Table 1 gives an overview of all stated reasons for and against the documentation and communication of subject areas. For ease of presentation, we present the reasons within one topic area together. In case a patient gave one reason for more than one variable, it counted multiple times.

We could develop a few categories on the decision about documenting PRO data over time. One patient stated that previous and current therapies, itch and PRO data in general, as well as the body surface area and severity should be documented over time. Reasons for a documentation of the latter were also given: detection of treatment effects, better assessment of clinical values, and relevance for further treatment. Documenting the first appearance of symptoms over time is unnecessary for another patient.

Examples of original quotations can be found in the Supplementary data.

\section{Integration of Focus Group Results in Expert Delphi Rounds}

In two online Delphi rounds, psoriasis experts allocated each of the variables presented above to a core, optimum, and optional data set (core=minimally to be documented; optimum=ideally to be documented; optional=optionally to be documented). The qualitative results presented within this manuscript served as a basis for discussions of the psoriasis experts within the inperson meeting (third Delphi round). At the beginning of the in-person meeting, a summary of all focus group results was given to the experts for each topic area. Afterwards, reasons were pointed out, in particular,

- that showed differences to the results of the prior online expert Delphi rounds (eg, physicians/physician groups involved in treatment, educational status, documentation of previous and current patient education),

- that concerned patient specific results (eg, PRO),

- and when experts had difficulties in finding consensus.

After the in-person meeting, further online Delphi rounds were conducted. The final results of the Delphi study will be published elsewhere. 
Table I Topic and Subject Areas, Main and Subcategories

\begin{tabular}{|c|c|c|}
\hline Topic Area & Subject Area & Main and Subcategories \\
\hline Overall topic & In the focus groups discussed variables & $\begin{array}{l}\text { Main categories: indicate whether a stated reason was given for or against the } \\
\text { documentation of a variable } \\
\text { Subcategories: stated reasons for or against the documentation of a variable }\end{array}$ \\
\hline \multirow[t]{4}{*}{$\begin{array}{l}\text { Personal } \\
\text { data }\end{array}$} & \multirow{4}{*}{$\begin{array}{l}\text { I. Insurance status } \\
\text { 2. Previous and current occupation } \\
\text { 3. Marital status } \\
\text { 4. Previous pregnancies } \\
\text { 5. Current family planning } \\
\text { 6. Family history of psoriasis } \\
\text { 7. Gender } \\
\text { 8. Age } \\
\text { 9. Educational status } \\
\text { 10. Height } \\
\text { II. Weight } \\
\text { 12. Body mass index } \\
\text { 13. Waist and hip circumference/ratio } \\
\text { 14. Smoking behavior } \\
\text { 15. Drinking behavior (alcohol) } \\
\text { 16. Nutrition }\end{array}$} & $\begin{array}{l}\text { Reasons for a documentation of variables of personal data; } \vee \text { (variables)=if reason } \\
\text { was stated for more than one variable }\end{array}$ \\
\hline & & $\begin{array}{l}\text { - } \vee \text { have an impact on psoriasis }(n=27) \\
\text { - } V \text { have an impact on choosing therapy }(n=26) \\
\text { - } V \text { for knowing about hereditary risks }(n=5) \\
\text { - } V \text { can help identifying statistical characteristics of psoriasis }(n=5) \\
\text { - } V \text { are necessary for physicians/patients }(n=4) \\
\text { - Age can indicate different periods and handling of the disease by different age } \\
\text { - groups }(n=4) \\
\text { - Previous pregnancies can lead to changes/beginning/ending of psoriasis }(n=2) \\
\text { - Current and previous occupation for knowing about impairments at work }(n=1)\end{array}$ \\
\hline & & $\begin{array}{l}\text { Reasons against a documentation of variables of personal data; } \vee \text { (variables)=if } \\
\text { reason was stated for more than one variable }\end{array}$ \\
\hline & & $\begin{array}{l}\text { - } \checkmark \text { have no impact on psoriasis }(n=22) \\
\text { - } V \text { have no impact on therapy }(n=9) \\
\text { - Insurance status is not necessary for physicians and/or patients }(n=3) \\
\text { - Documentation of drinking and smoking behavior can lead to hasty conclusions } \\
\text { - by physicians }(n=2) \\
\text { - Documentation of educational status might be against norms and values }(n=I) \\
\text { Marital status has no added value }(n=1)\end{array}$ \\
\hline \multirow[t]{4}{*}{$\begin{array}{l}\text { Anamnesis } \\
\text { data }\end{array}$} & \multirow{4}{*}{$\begin{array}{l}\text { I. First appearance of symptoms } \\
\text { 2. Initial diagnosis } \\
\text { 3. Comorbidity } \\
\text { 4. Comedication } \\
\text { 5. Previous rehabilitative measures due } \\
\text { to psoriasis } \\
\text { 6. Current rehabilitative measures due } \\
\text { to psoriasis } \\
\text { 7. Previous inpatient stays due to } \\
\text { psoriasis } \\
\text { 8. Current inpatient stays due to } \\
\text { psoriasis } \\
\text { 9. Previous inability to work due to } \\
\text { psoriasis } \\
\text { 10. Current inability to work due to } \\
\text { psoriasis } \\
\text { II. Previous and current therapies } \\
\text { 12. Clinical form of psoriasis }\end{array}$} & $\begin{array}{l}\text { Reasons for a documentation of variables of anamnesis data; } V \text { (variables) }=\text { if reason } \\
\text { was stated for more than one variable }\end{array}$ \\
\hline & & $\begin{array}{l}\text { - } \checkmark \text { to document experiences about the effectiveness of measurements }(n=20) \\
\text { - } \vee \text { have an impact on medication }(n=5) \\
\text { - } \vee \text { to manage drug-drug interactions }(n=4) \\
\text { - Documentation of the first appearance of symptoms and initial diagnosis can lead } \\
\text { to better integrated care }(n=2) \\
\text { - Documentation of the first appearance of symptoms and initial diagnosis can } \\
\text { indicate different handling of the disease }(n=2) \\
\text { - Documentation of the first appearance of symptoms and initial diagnosis can } \\
\text { overcome insufficient memory }(n=2) \\
\text { - Documentation of the first appearance of symptoms for indicating disease over } \\
\text { time ( } n=2) \\
\text { - Documenting previous and current therapies to be able to exclude diagnoses } \\
\text { - Documenting clinical form of psoriasis to indicate interactions between different } \\
\text { clinical forms of psoriasis ( } n=1)\end{array}$ \\
\hline & & $\begin{array}{l}\text { Reasons against a documentation of variables of anamnesis data; } V \text { (variables)=if } \\
\text { reason was stated for more than one variable }\end{array}$ \\
\hline & & $\begin{array}{l}\text { - } \vee \text { have questionable relevance }(n=5) \\
\text { - Documenting previous rehabilitative measures due to psoriasis can lead to hasty } \\
\text { conclusions by physicians }(n=1)\end{array}$ \\
\hline
\end{tabular}

(Continued) 
Table I (Continued).

\begin{tabular}{|c|c|c|}
\hline Topic Area & Subject Area & Main and Subcategories \\
\hline \multirow[t]{4}{*}{ Clinical data } & \multirow{4}{*}{$\begin{array}{l}\text { I. Body surface area and severity } \\
\text { 2. Adverse events in previous and current } \\
\text { therapies } \\
\text { 3. Laboratory results } \\
\text { 4. All clinical data (including I-3, nail } \\
\text { psoriasis, psoriasis arthritis) }\end{array}$} & $\begin{array}{l}\text { Reasons for a documentation of variables of clinical data; } \vee \text { (variables)=if reason } \\
\text { was stated for more than one variable }\end{array}$ \\
\hline & & $\begin{array}{l}\text { - } \vee \text { to document experiences with therapy/side effects }(n=4) \\
\text { - } \vee \text { have an impact on medication }(n=4) \\
\text { - Documenting body surface area and severity for capturing quality and quantity of } \\
\text { psoriasis }(n=1) \\
\text { - Documenting laboratory results over time for a better estimation of results } \\
(n=2) \\
\text { - Documenting all clinical data leads to knowledge about the state of psoriasis } \\
(n=1)\end{array}$ \\
\hline & & Reasons against a documentation of variables of clinical data \\
\hline & & - Body surface area and severity could be inadequately recorded $(n=2)$ \\
\hline \multirow{4}{*}{$\begin{array}{l}\text { Patient- } \\
\text { reported } \\
\text { data }\end{array}$} & \multirow{4}{*}{$\begin{array}{l}\text { I. Burden of disease/severity } \\
\text { 2. Itch } \\
\text { 3. Pain } \\
\text { 4. Symptoms } \\
\text { 5. Compliance } \\
\text { 6. Quality of life and health status } \\
\text { 7. Depression and anxiety } \\
\text { 8. Psychological burden } \\
\text { 9. Adverse events } \\
\text { 10. Treatment goals } \\
\text { 11. Treatment benefit } \\
\text { 12. Own treatment costs } \\
\text { 13. Burden of therapy } \\
\text { 14. Time requirements for treatment } \\
\text { 15. External help } \\
\text { 16. Satisfaction with treatment } \\
\text { 17. Patient-reported outcomes }\end{array}$} & $\begin{array}{l}\text { Reasons for a documentation of variables of patient-reported data; } V \text { (variables)=if } \\
\text { reason was stated for more than one variable }\end{array}$ \\
\hline & & $\begin{array}{l}\text { - } V \text { indicate individual burden }(n=8) \\
\text { - } V \text { allow subjectivity }(n=5) \\
\text { - Quality of life and everyday life are influenced by psoriasis }(n=3) \\
\text { - Documenting psychological burden, depression, and anxiety to recognize need } \\
\text { - for action ( } n=3) \\
\text { - Documenting own treatment costs to find efficient treatment opportunities for } \\
\text { - patients ( } n=3) \\
\text { - Documenting patient's goals for purposeful physician-patient consultation }(n=2) \\
\text { - Compliance is related to other aspects }(n=1) \\
\text { - Stating side effects is not subjective }(n=1) \\
\text { - Patient satisfaction indicates successful therapy }(n=1)\end{array}$ \\
\hline & & $\begin{array}{l}\text { Reasons against a documentation of variables of patient-reported data; } \vee \text { (variables) } \\
=\text { if reason was stated for more than one variable }\end{array}$ \\
\hline & & $\begin{array}{l}\text { - } V \text { are subjective }(n=6) \\
\text { - Patient-reported data could be stated intentionally false }(n=1) \\
\text { - Patient satisfaction has no impact on medication }(n=I)\end{array}$ \\
\hline \multirow[t]{4}{*}{ Other data } & \multirow{4}{*}{$\begin{array}{l}\text { I. Documentation of previous and cur- } \\
\text { rent patient education } \\
\text { 2. Physicians/physician groups involved in } \\
\text { treatment }\end{array}$} & Reasons for a documentation of variables of other data \\
\hline & & $\begin{array}{l}\text { - Lack of information, such as possible course or forms of disease }(n=6) \\
\text { - Enabling possible actions }(n=2) \\
\text { - Integrated care/exchange of information }(n=6) \\
\text { - Concerning different physician groups }(n=1)\end{array}$ \\
\hline & & Reasons against a documentation of variables of personal data \\
\hline & & $\begin{array}{l}\text { - Individual reaction on medication }(n=2) \\
\text { - No capacity for physicians }(n=2) \\
\text { - Hasty conclusions by physicians }(n=2)\end{array}$ \\
\hline
\end{tabular}

\section{Discussion}

The patients' attitudes showed strong agreement on the documentation of nearly all variables except for some controversially discussed personal data (insurance and educational status, waist and hip circumference/ratio, family history of psoriasis, gender, height, body mass index, and nutrition). In general, preference studies show high importance of items out of patients' point of view., 
This applies to other indications (eg, kidney disease), ${ }^{11}$ too. An explanation for this might be a lack of knowledge about the necessity of the variables serving for treatment decisions. Furthermore, as time is limited, not all variables can be documented or discussed with each patient with psoriasis. In our study, the patients did not have to decide on one or another variable, they did not have to trade off.

Resulting from this, the patients mainly mentioned reasons for documenting variables. They were aware that some variables had an impact on psoriasis or on the medication (or even no impact) and could help to document patients' experiences about their disease.

The attitudes towards following variables influenced the decision-making process of the psoriasis experts, in particular: PROs, patient education, and physicians involved in the treatment because management of psoriasis is complicated. ${ }^{1,12}$ There is also high knowledge within the literature about the need to strengthen the relationship between physicians and patients with psoriasis $^{13}$ and to optimize patient-centered care by considering PROs. ${ }^{1}$

In the presented focus groups, the patients argued whether each variable should be documented or discussed with a physician. This might be built on the patients' preferences and goals. To find out if our data are in line with existing results, we took patients' treatment goals into account.

Blome et al and Gutknecht et al summarized patients' treatment goals in psoriasis care and showed that having confidence in healing and reducing physical impairments contain the most important treatment goals for patients with psoriasis. ${ }^{6,8}$ Furthermore, getting better skin quickly and regaining control of the disease were other very important treatment goals. The findings presented herein strongly support this, as patient education should be documented to guarantee that patients are on state of affairs and are also able to control their disease. The necessity of documenting clinical data (eg, severity, nail psoriasis) as well as patient-reported data (eg, symptoms, pain, itch) shown in the focus groups goes in line with the indicated importance of reducing physical impairments in Blome et al. ${ }^{7}$ For the patients of the focus groups it was also important to document variables, such as clinical form of psoriasis, comorbidity, and therapies to record experiences and achieve clarity. The importance of finding clear diagnosis and therapy in Blome et al also supports our results. ${ }^{7}$ Duffin et al were also able to show patients' attitudes on the importance of documenting variables even though to assess psoriasis in clinical trials and not in clinical practice. ${ }^{9}$ They asked 15 patients within a Delphi study to vote on variables concerning clinical and anamnesis data. The patients placed most of the variables in the core data set, few variables in the optimum data set, and none in the optional data set (wording adapted to the Delphi approach described in this article).

Next, according to Blome et al, reducing impairments due to therapy followed by reducing psychological impairments were important goals for patients with psoriasis. ${ }^{7}$ For the patients of Blome et al, it was essential to be less dependent on doctor and clinic visits, having to spend less time with daily care, having fewer out-of-pocket treatment costs, and experiencing fewer side effects (reducing impairments due to therapy). ${ }^{7}$ The patients in the focus groups were of the opinion that previous and current therapies, previous and current inpatient stays due to psoriasis, previous and current rehabilitative measures due to psoriasis, etc (anamnesis data) should be documented due to the ability of detecting effectiveness of single treatments to ensure that insufficient therapies are not used again. Their attitudes also showed that adverse events, compliance, own treatment costs, burden of therapy, and time requirements for treatment were important and should be documented (PRO data). Some of the psychological impairments assessed in Blome et al are gaining in joy of living, being able to lead a normal everyday life, and normal leisure activities as well as being less depressed which is covered by PRO data in the focus groups. ${ }^{7}$ All PRO data emerged as important for the patients. This was also shown in other studies about documenting data in psoriasis trials. ${ }^{9,10}$

In comparison, reducing social impairments was less important to the patients in Blome et al. ${ }^{7}$ This is the case for being less of a burden to relatives and friends or less burdened in the partnership. In the focus groups, the patients strongly recommended to document and discuss external help and quality of life. The difference might be explained by the comparison of quantitative (Blome et al) ${ }^{7}$ and qualitative (focus groups) data. The variables might be very important to patients that, eg, depend on external help, but this might not have been the case for many patients in Blome et al. ${ }^{7}$ Whereas in the focus groups the sample might mainly have consisted of patients with moderate and severe psoriasis (see methods) and thus were more dependent on help. On the contrary, the necessity of documenting personal and private data goes in line with 
the results of Blome et al on social impairments being less important than the other aspects. ${ }^{7}$ Within the focus groups, the patients discussed personal data, which includes social aspects such as marital status, previous pregnancies, and current family planning.

Different healthcare sites have their own particular culture that is generalizable to a greater or lesser degree. This particular research site was one in which specialized care is provided resulting in care for patients with moderate to severe psoriasis. The opinions of patients with mild psoriasis might not be explored. However, for this approach being qualitative, generalizability was no aim and a broader, more meaningful range of reasons was expected by consulting patients with moderate to severe psoriasis, as the documentation will be especially relevant for this group.

We reached heterogeneity of the sample in terms of age, gender, and time of occurrence of symptoms, but mainly included patients with higher educational degrees. For a qualitative approach this can be beneficial (see above). Quantitative approaches to answer our research question should consider differences within these groups. Scala et al showed an influence of patients' demographic and socioeconomic characteristics on their received prescription. ${ }^{14}$ For future documentation healthcare providers should aim to equally document patient data to ensure high and equal quality of care for all patients.

\section{Conclusions}

On the one hand, the focus group results supported psoriasis experts' decision-making on a data set for a documentation in clinical practice. Thereby, PROs, patient education, and physicians involved played an important role. On the other hand, the results can help to understand patients' preferences and their idea of an exhaustive doctor-patient consultation in general. Taking the variables and reasons into account can lead to better patient empowerment and quality of care. In the next step, the final data set will be developed and classified by psoriasis experts and scientists for use in clinical practice and for unifying documentation of psoriasis. The data set will also form the basis for an electronic monitoring and documentation system to improve the management of psoriasis, physician and patient communication, and patient empowerment.

\section{Acknowledgments}

The authors would like to thank the participants of the study for their valuable contribution as well as the nursing and medical staff of the outpatient care unit involved in supporting recruitment of the study. We would also like to thank the following institutions for their valuable cooperation: German Society of Dermatology (DDG), Professional Association of German Dermatologists (BVDD), Regional Psoriasis Networks in Germany (PsoNet). The authors thank the Scientific Communication Team of the IVDP, in particular, Mathilda Meyer and Mario Gehoff, for copy editing.

\section{Funding}

The study was generally funded by Celgene, but the sponsor had no role in designing the study or analysis or interpretation of the data as well as the decision whether or not to submit its results.

\section{Disclosure}

The authors declare no potential conflicts of interest with respect to the research, authorship, and/or publication of this article.

\section{References}

1. World Health Organization (WHO). Global report on psoriasis; 2016. Available from: https://apps.who.int/iris/bitstream/handle/10665/ 204417/9789241565189_eng.pdf?sequence=1\&isAllowed=y.

Accessed August 22, 2019.

2. Stern RS, Nijsten T, Feldman SR, Margolis DJ, Rolstad T. Psoriasis is common, carries a substantial burden even when not extensive, and is associated with widespread treatment dissatisfaction. $J$ Investig Dermatol Symp Proc. 2004;9(2):136-139. doi:10.1046/j.10870024.2003.09102.x

3. Kimball AB, Jacobson C, Weiss S, Vreeland MG, Wu Y. The psychosocial burden of psoriasis. Am J Clin Dermatol. 2005;6(6):383-392. doi:10.2165/00128071-200506060-00005

4. Schmitt J, Apfelbacher C, Spuls P-I, et al. The Harmonizing Outcome Measures for Eczema (HOME) roadmap: a methodological framework to develop core sets of outcome measurements in dermatology. $J$ Invest Dermatol. 2015;135(1):24-30. doi:10.1038/jid.2014.320

5. Leung FK, Savithiri R. Spotlight on focus groups. Can Fam Physician. 2009;55(2):218-219.

6. Blome C, Augustin M, Behechtnejad J, Rustenbach SJ. Dimensions of patient needs in dermatology: subscales of the patient benefit index. Arch Dermatol Res. 2011;303(1):11-17. doi:10.1007/s00403-0101073-0

7. Blome C, Gosau R, Radtke MA, et al. Patient-relevant treatment goals in psoriasis. Arch Dermatol Res. 2016;308(2):69-78. doi:10.1007/ s00403-015-1613-8

8. Gutknecht M, Schaarschmidt ML, Danner M, Otten M, Augustin M. How to weight patient-relevant treatment goals for assessing treatment benefit in psoriasis: preference elicitation methods vs. rating scales. Arch Dermatol Res. 2018;310:567-577. doi:10.1007/s00403-0181846-4

9. Duffin KC, Merola JF, Christensen R, et al. Identifying a core domain set to assess psoriasis in clinical trials. JAMA Dermatol. 2018;154 (10):1137-1144. 
10. Feldman SR, Regnier SA, Chirilov A, Hey F, Gilloteau I, Cella D. Patient-reported outcomes are important elements of psoriasis treatment decision making: a discrete choice experiment survey of dermatologists in the United States. J Am Acad Dermatol. 2018;80 (6):1650-1657. doi:10.1016/j.jaad.2018.09.053

11. Ormandy P, Hulme C. Measuring patients' preferences and priorities for information in chronic kidney disease. Inf Res. 2013;18(3): paper588.

12. Chawla S. A novel approach to outpatient clinic management. $\mathrm{Br} J$ Dermatol. 2019;180(6):1560-1561. doi:10.1111/bjd.17643
13. Larsen MH, Hagen KB, Krogstad AL, Wahl AK. Shared decision making in psoriasis: a systematic review of quantitative and qualitative studies. Am J Clin Dermatol. 2019;20(1):13-29. doi:10.1007/ s40257-018-0390-5

14. Scala E, Megna M, Amerio P, et al. Patients' demographic and socioeconomic characteristics influence the therapeutic decisionmaking process in psoriasis. PLoS One. 2020;15(8):e237267. doi:10.1371/journal.pone. 0237267

\section{Publish your work in this journal}

Patient Preference and Adherence is an international, peer-reviewed, open access journal that focusing on the growing importance of patient preference and adherence throughout the therapeutic continuum. Patient satisfaction, acceptability, quality of life, compliance, persistence and their role in developing new therapeutic modalities and compounds to optimize clinical outcomes for existing disease states are major areas of interest for the journal. This journal has been accepted for indexing on PubMed Central. The manuscript management system is completely online and includes a very quick and fair peer-review system, which is all easy to use. Visit http:// www.dovepress.com/testimonials.php to read real quotes from published authors. 